\title{
Integrating Industry-Specific Training into Mainstream University Computer Science Curriculum: Case of SMU
}

\author{
T. Hungwe ${ }^{1, *}$, T. A. Dandadzi ${ }^{1}$, S. M. Seeletse ${ }^{2}$ \\ ${ }^{1}$ Department of Computer Science, Sefako Makgatho Health Sciences University, Molotlegi Street, Ga Rankuwa, 0208, Gauteng \\ Province, South Africa \\ ${ }^{2}$ Department of Statistics and Operations Research, Sefako Makgatho Health Sciences University, Molotlegi Street, Ga Rankuwa, 0208, \\ Gauteng Province, South Africa
}

Received May 7, 2021; Revised June 18, 2021; Accepted July 19, 2021

Cite This Paper in the following Citation Styles

(a): [1] T. Hungwe, T. A. Dandadzi, S. M. Seeletse, "Integrating Industry-Specific Training into Mainstream University Computer Science Curriculum: Case of SMU," Universal Journal of Educational Research, Vol. 9, No. 8, pp. 1589 1598, 2021. DOI: 10.13189/ujer.2021.090811.

(b): T. Hungwe, T. A. Dandadzi, S. M. Seeletse (2021). Integrating Industry-Specific Training into Mainstream University Computer Science Curriculum: Case of SMU. Universal Journal of Educational Research, 9(8), 1589 - 1598. DOI: 10.13189/ujer.2021.090811.

Copyright $\bigcirc 2021$ by authors, all rights reserved. Authors agree that this article remains permanently open access under the terms of the Creative Commons Attribution License 4.0 International License

\begin{abstract}
Changes in industry promote curriculum reforms in education, especially in higher education, which serves as an industry feeder. The need to renew the Computer Science curriculum (CSC) is critical because it is dynamic and constantly evolves as the axis of modern technology. Integrating the industry's needs into the CSC can be a useful strategy for keeping up with such changes. A number of countries in Europe and beyond have developed ways in bringing vocational training into mainstream university curriculum. This paper discusses the significance of integrating industry-specific training (IST) into the existing CSC in higher education. The Sefako Makgatho Health Sciences University, South Africa is used as an example. This integration combines standard academic CSC content with beneficial, carefully selected industry aspects. The study followed a qualitative design, which encompassed the ideas and perceptions of the students enrolled at the time, experiences of former students who are employed in the computer science industry, and lecturers. Data were collected using questionnaires, directed to each stratum. Thematic content analysis was used to analyse the data. Results from the study were satisfactory and affirmed that, IST integration into the CSC is valuable, helps build networks and integrates timely mentorship into the world of work in the students.
\end{abstract}

Keywords Computer Science Curriculum, Futuristic
Curriculum, Industry-Specific Training, Integration

\section{Introduction}

This Industry-specific training (IST) provides knowledge and qualifications in a given industry or sector. Times IST is referred to as vendor-specific or sector-specific training. By nature IST certifications are traditionally industry specific training-oriented, extremely technical in nature and as such, complement academic knowledge, core concepts, computing practices and learning experiences in Computer Science (CS) [1]. Such training is required as employers seek graduates who are 'job ready', who immediately on employment are productive and who do not need further training in what they are supposed to achieve.

A number of higher education training programmes in Europe and beyond have implemented IST integration. Among these are German [2], Australia [3], Israeli [4], United Kingdom, United States, and Japan [5], which have linked academic and work-based learning in vocational academies, polytechnic colleges, and universities of technologies and mainstream universities. Such practices are vital for value addition to academic programmes as authentic practices, collaborative problem 
solving, removal of artificial boundaries between content, practices and context of learning experiences, gap reduction between learning theory and real-life practice and empowerment of graduates, among others are achieved [1].

Integration of IST entails building effective networks for students to engage in purposeful and relevant industrial and societal activities [6-8]. This also equips students with necessary competencies in order for them to become functional citizens [9]. As such, industrial and academia partnerships are encouraged which could provide for engagements between academia and related industries. The Department of Computer Science (DCS) at Sefako Makgatho Health Sciences University (SMU), South Africa is integrating IST into mainstream university computer science curriculum (CSC). The CSC courses are offered in the Computational and Mathematical Science (CMS) stream of the Bachelor of Science (BSc) degree programme.

CSCs first year BSc CMS degree courses include Computing Concepts and Algorithms (CCA), Data Organisation and Artificial Intelligence (DOAI), C++ programming $(\mathrm{C}++)$, Object-Oriented Programming (OOP) and Web Development (WD). The second year courses are Data Structures (DS), Systems Analysis and Design (SAD), Computer Organisation and Architecture (COA). In the third year, the courses are Introduction to Database Systems (DBS), Software Engineering (SE), Java Programming (Java) and Computer Networks (CN). Besides these modules available to the three-year BSc degree programme, the same modules are also available in the four-year BSc Extended Curriculum Programme (ECP). ECP 1 students are offered the first-semester modules of the first year of the three-year mainstream BSc programme. Thus the ECP 1 year programme constitute half of the year modules of the first year in the three-year B.Sc degree programme. The second-semester first-year modules offered to the first years in the three-year degree programme are then presented in the second year for ECP 2 students. At the end of ECP 2, the ECP students would have completed all the first-year modules of the BSc degree, and then in their third year, they join the mainstream BSc programme at second-year level.

During their studies at SMU, CSC students are also exposed to industry training specific platforms such as Cisco Network Academy (Netacad) and Oracle University. This mainstream CS academic content is benchmarked with renowned universities locally and internationally. The industry-specific platforms offer content related to the specific industry. For example, IT Essentials offered by Netacad is a curriculum for first-line IT technicians. At the end of the programme, industry and the university provides their programmes to the students.

As CSC has undergone many changes worldwide, this has necessitated a review of CS at SMU. In 2015, the DCS submitted a reviewed CSC and was awaiting approval and accreditation from the Department of Higher Education and Training (DHET) and South Africa Qualification Authority (SAQA). CS discipline is ever-changing, SMU must integrate content relevant to the current needs of the discipline and the industry. For instance, DBS focuses on Procedural Language/Structured Query Language (PL/SQL) programming, which deals with the relevant technologies and programming using Oracle database systems. Due to the field's ever-changing nature, there is a need to review the curriculum regularly.

At SMU, a curriculum is expected to be revised every three (3) years. Thus the programme learning outcomes (PLOs) are revised accordingly with the Institutional Planning and Academic Development (IPAD) playing the facilitation role. IPAD encourages regular curriculum review and assists when academic departments in SMU introduce changes in the syllabi and/or initiate new study programmes. This division scrutinizes the inputs made for curriculum and syllabus changes and adjustments, and recommends improvements where they find it appropriate. The processes followed include: self-evaluation at department level, peer evaluations, and independent external board nominated by IPAD followed by an improvement plan with actions to respond to the results or weaknesses/deficiencies identified during the evaluation process based on the relevant higher education quality committee (HEQC) and council on higher education (CHE) and SMU-specific criteria. Workshops with external board is done taking the form of interviews of staff and students (current and former) as well as presentations by staff. This, in turn, is followed by progress reports. From the last review process, it was recommended that the department introduce more practical component in its module offering in order to prepare students for 4IR as well as partnering with more industry role players. The IPAD also encourages entrepreneurship as part of the curriculum, and hence its evaluation of IST incorporation in CS curriculum adjudges it as a welcome venture. This process generally requires the participation of Faculty and Senate Quality Assurance committees. The DHET's approval will be sought depending on the extent of the changes required. Changes to curriculum are classified into three types. Category A, which requires technical changes. Category B requires some curriculum development, and Category $\mathrm{C}$, which entails significant re-curriculation and necessitates a new programme [10]. It would then be sent from DHET to the Council on Higher Education (CHE) and to SAQA. Though necessary for regulating and adding value, this whole process delays the curriculum implementation. DHET, SAQA and CHE form part of the academic curriculum stakeholders.

Immediate academic stakeholders include lecturers and CSC students. Other stakeholders in academia are the CS head of department, IPAD, dean of the school of science and technology, deputy vice-chancellor, teaching, learning 
and community engagement, and the vice-chancellor and the industrial academic committee (IAC).

The IAC is intended to advice on the developments of CS and IT as well as their applications in industry, and thus in adjusting the academic curriculum to gradually incorporate CS content that is in line with the industry changes. The IAC is made up of an alumni member who majored in computer science and information technology and two relevant industry plays on rotational basis over a three-year period to be in line with the frequency of programme review. The mechanism used takes the form of a workshop with staff and students interviewed as well as presentations by department. The committee then provides a detailed improvement plan.

This paper investigates practical and suitable approaches to IST's integration, and implementation into the CSC. It seeks to gather evidence on best practices of integrating IST and other related concepts to the South African context. The study will include the rationality, significance to the field, intended outcomes and theoretical frameworks to support this approach. The rest of the paper is structured as follows: "Problem statement", "Context of the research", "Motivation of the study", "Integration", "Industry", "Curriculum", "Rationale", "Significance the study", "Intended outcomes", "Theoretical frameworks", "Methodology", "Results", "Discussions", "Conclusions" and "Recommendations",

\subsection{Problem Statement}

This study demonstrates the effectiveness of integrating IST in CSC. The initiatives proactively enhance employment chances and competitiveness. A strong relationship with the industry, together with students' empowerment by related industries, can offer some of the benefits of internships, apprenticeships, and WIL. This paper outlines how these benefits can be realised.

\subsection{Context of the Research}

IST is not commonly practised in South Africa higher education. WIL, on the other hand, is commonly used as an alternative to augment learning instruction in study programmes at universities of technology. This exposes students to the world of work at an early stage in their studies. Furthermore, universities are autonomous; their programmes vary from one another. This allows SMU to embrace innovation and added value in their CS research programmes.

\subsection{The Motivation of the Study}

Attributes leading to the ISP entailed a rationale for benefits based on criteria for improving learning quality and work readiness. The criteria used include that the core CS syllabus in SMU should not be lower than the best in the country and should match some of the international benchmarks. The CSC should appeal to the relevant industries and potential employers of SMU graduates.

\subsection{Integration}

This paper focuses on the integration of industry-specific training programmes into CSC for enhanced learning. Integration focuses on constructing meaningful connections for students to enable them to engage in purposeful and relevant activities [6,7]. The relevant activities are grounded in the world-of-work being incorporated into the classroom. Real industrial life experiences are provided to students before entering the job market. This could help in aligning the academic learning context with the world-of-work environment. Students can relate and integrate novel, authentic work experiences into classroom work and actively develop their skills and competencies [11]. ISP also provides students with opportunities for applied research. The integration provides academics with the opportunity to have a renewed vision to prepare future graduates with an enhanced curriculum. It, therefore, provides rich, exciting, and worthwhile teaching and learning experiences for both students and lecturers. The integrated curriculum can also provide links between different study areas such as, across CS and Statistics, especially in areas of computation and artificial intelligence. This promotes interdisciplinary collaboration, which helps unify concepts taught across disciplines.

\subsection{Industry Curriculum}

Industry-specific curriculum content includes software and hardware products for the CS discipline. The software includes Microsoft (MS) office suite (MS Word, Excel, Access, and PowerPoint) and hardware products include routers and switches. The content necessary to become an expert as an International Business Machines Corporation (IBM) database administrator requires Database II (DB2). Similarly, some of the industry-specific curriculum materials for other expertise is Oracle's PL/SQL programming, Cisco Certified Network Associate Routing and Switching (CCNA), and A+ [1].

A positive aspect of these offerings is that, corporate competitors may partner for a common purpose of social responsibility in academia towards a common purpose. As a way of integrating industry-specific curriculum content at SMU, the DCS has engaged in partnerships with competing CS-related companies and organisations. These companies and organisations include Oracle, Cisco, IBM, Council for Scientific and Industrial Research (CSIR) and Cengage Learning publishing company.

Oracle University, Huawei and Cisco Netacad have accredited SMU as their academies. Many courses and certifications under the Oracle Academy include PL/SQL 
programming, system administration, database analytics, big data and Oracle database administration. SMU has offered DB2 to the final-year students via IBM South Africa, leading to IBM associate certification. Some industrial companies and organisations are also making their content available through their online training platforms. These platforms include Netacad, Oracle University, Huawei and Cengage.

These IST offerings have benefits that include research and teaching and learning of CS at SMU. They have also increased productivity and efficiency in teaching materials and content. The lecturers customize the teaching materials to suit the intended teaching and learning outcomes. The Cengage Learning publishing company's content and materials are easily integrated into the SMU learning management system. The industry-specific content and the theoretical framework is valuable in addressing such integration.

\subsection{Rationale}

The importance of integrating the IST into mainstream university CSC is fundamentally inestimable. Integration involves mixing the existing CSC syllabus content and the corresponding applications from the industry. Integrating IST into mainstream university $\mathrm{CSC}$ at SMU was to include industrial practice into the lecture content. Such an approach enriches the students' quality of participating in CS courses with IST integration. Other world leading universities are using the approach as best practice [12]. Integration also brings industrial expertise to academics and students. Among other things, IST offers a direct contact of industry experts with students, which markets the graduates' for employment. It also provides the requisite professional certification qualification (PCQ)

The PCQ is equivalent to in-service training or courses offered while the incumbents are already in the workplace in order to equip them with skills and knowledge of best practice according to emerging trends in the market. The training given uses some of the aspects of service learning, apprenticeship, intern or work-integrated learning and as a result, provides induction that new employees are given when they enter a new job.

\subsection{Significance of the Study}

This integration is viewed as implementing best practice in the teaching and learning process [6,7]. The approach provides for the solicitation of experts with industry-related knowledge and skills to consolidate and complement the CSC learning content. It provides the missing gap between academic work, real-life experiences, and industry activities. This implementation of IST into the mainstream university curriculum also provides opportunities for pragmatic evidence collection on the way universities can improve the integration process $[6,7]$.
In this way, CSC becomes responsive to real-life issues, and the ever-changing body of knowledge. The value-added aspect leads to graduates' more tremendous potential to be employed with relative ease and opportunities to address industry problems through academic research. The graduates can also become entrepreneurial and not necessarily limited to job seeking. Fundamentally, such curriculation could be a driving force towards the relevance of content, skills, knowledge and learning methods in teaching and learning, psychological, social, cultural, and economic environments $[13,14]$. Above all, CSC should be responsive to real-life issues, and an IST is a crucial opportunity for that.

\subsection{Intended Outcomes}

Integrating IST into mainstream university $\mathrm{CSC}$ at SMU instils industry exposure and expertise into its formative development. It brings real-world experiences to the students, thereby enriching students' quality attributes. There are underpinning frameworks that guide the implementation of such an integrated approach to achieve the outcomes.

\subsection{Theoretical Framework}

The concept of integrating IST into the mainstream university curriculum is grounded in the futuristic curriculum [15]. The futuristic curriculum's rationale is restructuring the existing curriculum to meet global changes and challenges in the digital age, which covers current demands and future requirements. Futuristic curriculum development and integration of IST enable academia to adopt transforming ideas from research and the world of work.

Futuristic theory can also be related to the constructivist theory, which states that learners construct knowledge through their experiences and associated pedagogical approaches that promote active learning or learning by doing [16]. The curriculum could be future-oriented while still serving the current needs. It enables graduates who can do what is required in the future. It is therefore flexible and has a perpetual lifespan that is similar to the ever-changing CS discipline. This description entails using the flipped classroom (FC) or inverted classroom [17-20]. FC entails an instructional strategy and blended learning that boost traditional learning by delivering instructional content, primarily online, using several media and technologies outside the classroom [21]. The FC approach, therefore, relocates learning activities, including the ones that are customarily been regarded as homework into the classroom.

Learners in an FC tend to benefit significantly from online lectures. They collaborate in online discussions, execute learning, and research activities at home or elsewhere, and engage in applying concepts guided by a 
mentor [22]. The FC deliberately swings instruction to a learner-centred model in which class time investigates topics in more depth and generates meaningful learning opportunities. Educational technologies such as online videos are used to deliver learning content outside the classroom. Content delivery through FC may take different forms. Often, video lessons are used to deliver content.

An FC maybe combined with online collaborative discussions, digital research, and text readings. FC increases students' engagement that stimulates positive learning attitudes and shifts learning from group learning space to an individual self-paced learning space [6, 23]. $\mathrm{FC}$ can also be viewed as a kind of Blended Learning (BL) approach [24-26] which involves mixing and meticulous integration of classroom face-to-face (f2f) learning experiences with online experiences. This provides for the well-balanced combination of in-class and out-class activities. Technology is key to FC and BL approaches, which provides for multiple delivery media designed to complement f2f learning [27].

The IST's integration in the mainstream university curriculum is grounded in the FC, BL approaches and futuristic curriculum as presented above. These are enhancers of modern learning, without which competitive education cannot survive.

\section{Methodology}

The study design is qualitative. The action research approach is adopted in a proactive initiative to make the CSC attractive to the industry. Action research sketches what is missing or what is needed and then researches what needs to be done to address the gap [28]. Thus develop problem awareness which would provide objective implementable findings. The study would provide suggestions to what could be implemented practically to the curriculum changes.

An open-ended questionnaire was distributed to solicit participants' responses to their views after completing both IST and standard CSC. The study participants included students enrolled in the current university curriculum at SMU, former students currently employed in the CS industry and CS academic staff on several HEIs. CS incorporated some IST in their offerings, as illustrated in Table 1.

A total of 20 respondents participated in this study. Initial data used came from the original pilot study of three (3) participants. Based on the revisions and illustration in this paper, an additional data collection method was used to solicit responses and augment data. The additional data was gathered from three (3) SMU lecturers, six (6) other lecturers from other universities (Unisa, Wits, NWU, TUT), and five (5) third-year BSc. CS students. The open-ended questionnaire probed the five (5) aspects in bullet points under the results section. The data analysis was done using thematic content analysis to determine the respondents' impressions about ISP. In support for the ISP, the issues questioned and elucidated the study participants' wishes and the models they want the ISP to follow.

Table 1. Modules that have integrated industry-specific training

\begin{tabular}{|l|l|l|}
\hline BSc Level & SMU module & Industry-Specific training \\
\hline BSc I & MCOA011 (C++) & C ++ \\
\hline \multirow{2}{*}{ BSc II } & MCOA022 (COA) & Internet of Things (IoT), IT Essentials, NDG Linux \\
\hline \multirow{2}{*}{ BSc III } & MCOA031 (Pl/SQL Programming) & PL/SQL Programming \\
\cline { 2 - 3 } & MCOB031 (Networking) & IT Essentials, IoT, Cybersecurity \\
\hline
\end{tabular}




\section{Results}

Five (5) open-ended questions were distributed:

- Whether (and how) industry-specific training such as PL/SQL and IoT assists and contributes to the CS studies and career choices.

- Whether (and how) industry-specific training such as PL/SQL and IoT hinder CS studies and career choices.

- What benefits emerged from doing the ISP?

- What problems emerged from doing the ISP?

- What is the overall contribution of the integrated courses? Kindly provide explanations for experiences and other aspects concerning the integrated courses.

The following responses capture the range of benefits, value addition and aspects of the best practices, which are derived from integration of IST in CSC as provided by participants:

\section{Participant A:}

"Overall these courses were brilliant in a sense of clarifying the different CS fields available to us and also solidifying our CVs for potential work"

Participant B:

"Understanding the 4th Industrial Revolution and the opportunities available with it"

Participant C:

“... I got to learn about Oracle PL/SQL and also apply it in my final year project"

\section{Participant D:}

"It was an eye opener, gave brand new perspectives and broaden the scope"

\section{Participant E:}

"It assisted for knowing how to make good use of the internet in studies and it also provides electronic materials for easy studies or makes studying easy."

\section{Participant F:}

"It assist in knowing how to carry out online transactions, most things are going online and to know, helps to keep students abreast of what is going on in the society."

\section{Participant G:}

"In overall I think it will be advantageous to take these courses as the benefit derived from it cannot be over emphasised. Since the benefits outweigh the danger that can result from not doing it. It much better to go ahead with it."

None of these participants indicated any hindrances that could have been caused by IST integration. They concurred that integration provides a deeper meaning and understanding of the CS concepts offered, and this was the general trend from all the student participants' views and experiences. Such an adoption then, of IST into CSC, maintains the relevance of what academia offers to the students, who would later join the industry [29]. Thus, this justifies a shift towards ISP in the academic approach and to emphasise what is more important for students to understand concepts in CS that can support them in their career advancement.

The integration motivated the participants to solve industry problems while they were still studying. This implies that ISP assisted their CS studies with relevant exposure. In terms of career choices, the participants had desired to be in the professionals they interacted with in the CS environment and envisioned themselves in those settings. In the aforementioned scenarios, this assisted the participants in choosing a CS career as mentioned by participants. None of these participants indicated any hindrances towards their studies and job opportunities that IST integration could have caused. Instead, they concurred that integration provides a more profound meaning and understanding of the concepts taught and did assist in choosing their careers.

The participants agreed that they had benefitted from the integration of IST into mainstream university CSC. The adaptation of IST into CSC maintains the relevance of what academia offers to the students, who will later join the industry [29]. Hence, this justifies a change in the academic approach to consider integration and emphasise what is more important for students to understand CS concepts that can support them in their career advancement. The participants believed that they had the edge over those who were not exposed to the integration. This was evidenced by their struggling colleagues who were not exposed to IST, and which was demonstrated in their recruitment/selection for the positions they are currently occupying.

The findings show that the students are impressed with the contact with accurate and relevant industries. On the other hand, the industries have indicated that they plan to increase the interns from the student groups that use their training services. Positive results have been demonstrated. A few students who participated in a similar initiative as part of piloting, were given an internship and later employed permanently.

Curriculum enhancement could also benefit as a result of ISP enhancement. Since the existing curriculum will still be presented, the industry augmentation is added to it through IST. Students can experience real-life work settings and some industrial problems while learning theory. As a result, they can experiment with theoretical models, adapt them through practice, and even update them when necessary. Such a form of learning becomes fun while being fortified.

None of these participants indicated any hindrances that could have been caused by IST integration. They concurred that integration provides a deeper meaning and 
understanding of the CS concepts offered, and this was the general trend from all the student participants' views and experiences. Such an adoption then, of IST into CSC, maintains the relevance of what academia offers to the students, who would later join the industry [29]. Thus, this justifies a shift towards ISP in the academic approach and to emphasise what is more important for students to understand concepts in CS that can support them in their career advancement.

The integration motivated the participants to solve industry problems while they were still studying. This implies that ISP assisted their CS studies with relevant exposure. In terms of career choices, the participants had desired to be in the professionals they interacted with in the CS environment and envisioned themselves in those settings. In the aforementioned scenarios, this assisted the participants in choosing a CS career as mentioned by participants. None of these participants indicated any hindrances towards their studies and job opportunities that IST integration could have caused. Instead, they concurred that integration provides a more profound meaning and understanding of the concepts taught and did assist in choosing their careers.

The participants agreed that they had benefitted from the integration of IST into mainstream university CSC. The adaptation of IST into CSC maintains the relevance of what academia offers to the students, who will later join the industry [29]. Hence, this justifies a change in the academic approach to consider integration and emphasise what is more important for students to understand CS concepts that can support them in their career advancement. The participants believed that they had the edge over those who were not exposed to the integration. This was evidenced by their struggling colleagues who were not exposed to IST, and which was demonstrated in their recruitment/selection for the positions they are currently occupying.

The findings show that the students are impressed with the contact with accurate and relevant industries. On the other hand, the industries have indicated that they plan to increase the interns from the student groups that use their training services. Positive results have been demonstrated. A few students who participated in a similar initiative as part of piloting, were given an internship and later employed permanently.

The students' outcomes indicate that without the training obtained from IST content, students would not have been able to develop a CV that attracts employers, they would not have understood 4IR and its opportunities, it eased use of the knowledge to complete a compulsory research project, enabled use of internet and other online applications, among others. The partnership we have with specific industry role players in the likes of CISCO and Huawei has seen more than 15 of our final year students obtaining certification and 10 of those employed by their business partners in the telecommunications sector of the economy.

Curriculum enhancement could also benefit as a result of ISP enhancement. Since the existing curriculum will still be presented, the industry augmentation is added to it through IST. Students can experience real-life work settings and some industrial problems while learning theory. As a result, they can experiment with theoretical models, adapt them through practice, and even update them when necessary. Such a form of learning becomes fun while being fortified.

All The bureaucracy of governance constraints higher education, while educational programmes need to change continuously. In the heart of higher education is the need to produce working professionals, either as employees in sectors or employers of other people. This study could serve as a robust approach to ensure the type of graduates' attributes which are focused on economic contribution by making the graduates immediately employable after graduation. This need is also not restricted to computer science, but to any subject discipline in higher education, which desires to produce instant economic contributors from their study programmes.

At the successful end of the programme, both industry and the university provide certification (for achievement) of their programmes to the students. Therefore, participating students who complete both programmes are awarded SMU degrees with certificates at a dedicated university graduation ceremony and a certificate of practical exposure/professional competency in the IST. These certifications are professional and globally accepted [1]. This is rationalised as value addition, and employers seek graduates who are "job ready". Therefore, academia is impressed to mimic and mirror global work environments. Moreover, vendor-specific certifications are traditionally industry-specific training-oriented, highly technical and, as such, complement academic knowledge, core concepts, computing practices and learning experiences [1]. The integration provides an opportunity for the students to solve industry problems or real-world problems while they are still studying through the project choices they embarked on. This also helped the students envisage career choices available in the CS field.

In African higher education, incorporating relevant content for economic development is an urgent requirement to stabilise the countries. Economic instability breeds political volatility. When African countries can develop graduates who can make significant contributions to their economies, people's movement to other countries can be reduced with higher employment rates. When their own country's economy is in turmoil, people flee to more economically stable or prosperous countries. As a result, any educational programme that promotes economic development has the potential to contribute to political stability. The study could also serve as a benchmark on aspirations to produce instantly employable graduates and extending these to the entire 
nation and the whole African continent would, in the long term, could lead to economic development and political stability on the continent.

\section{Discussion}

This section reflects on the research question: How can industry specific training (IST) be best incorporated into CS in South African Higher Education (SAHE)? There is emphasis from the responses that IST should be integrated into the CSC. Integration entails building effective networks for students to engage in purposeful and relevant industrial and societal activities [6,7]. The integration of IST could be incorporated in the phases of the curriculum development process. Data were collected from relevant stakeholders, which included students, former students, who were employed in computer science related industries and academics. For the second stratum, the former CS students were employed at IBM, and Huawei organisations among others. Industrial and academia partnerships are encouraged. These partnerships would bring and integrate pragmatic industry focused projects into CS facilitation. Addressing real world problems can enhance the value of the CS graduates' attributes, as the graduate would have been challenged through the completion of such real-world projects to solve societal and economic needs. It also helps to connect the academic learning context with the world-of-work. Students can relate and integrate novel, authentic work experiences into classroom work and actively develop their skills and competencies [11].

Such relationships develop knowledge about each other, that is, industry, students and academia and thus advance each other's aspirations and goals. Academia can ease the transition of students from schooling to the workplace by benchmarking working environment technologies and team projects similar to the world of work. Addition of industry focused modules to provide industrial practices such as WIL could also be introduced in order to provide hands-on experiences to the students in preparation for the job market.

Notwithstanding the benefits, IST programmes to which SMU exposes its graduates to, have other challenges and limitations. The students are limited to only being employable in those specific CS companies because vendor products are not one-size-fits-all. Hence, a graduate with vendor-specific product knowledge might struggle with different environments or platforms. However, having a grounded understanding in CS and IT systems of a given or particular organisation makes a lot of difference in changing circumstance and adopting to the other organisations systems.

The accomplishments of integration of the IST programmes in the CSC are notable. It helps restructure the present curriculum by aligning it with what is required in the work environment. This could transform new ideas from research to the world of work. Active teaching and learning activities are enhanced. Best practices, such as learner-centeredness and self-paced models, are implemented to generate meaningful, in-depth and more profound learning opportunities. Collaboration among experts from the industry (including corporate rivals) with academics and students could provide platforms to exchange ideas. This improves the quality of the CS graduates. Among other things, there are improved chances of employment, value-addition, cost-saving, mentorship of students, bridging the gap between theoretical knowledge and industry expertise, and benchmarking academic teaching to the world of work. As CSC becomes responsive to real-life issues through IST, the CSC becomes modernized and up to date. Thus, having received the employer's training and qualified at SMU, could help these students to a better chance of being employed by these participating companies (which would have collaborated in the integration of their IST into SMU curriculum).

However, some questions need to be addressed in CSC. These are relevance, the CS degree programme content, depth of content in a three-year degree programme, the relevance of industrial partnerships and internships, and the timing of teaching and learning the integrated programme in terms of the timeframes fitting into the current calendar. Other questions could relate to regulatory bodies such as schools, faculty bodies, Senate, DHET, SAQA, and CHE for curriculum enrichment and accreditation purposes. These could be open to further research.

\section{Conclusions}

The proposed CSC should respond to the body of knowledge and the world of work as in the above discussions. Since business is ever-changing, it may necessitate a change in the body of knowledge and therefore warranting curriculum adaptation. Participants who had IST exposure during their studies felt that they had an advantage over those who had not been exposed to IST integration. Company initiatives (Cisco and Oracle) appeal to have education institutions train for the job market. Active learning to instill security awareness to our students initiates the students to solve the Cybersecurity threats experienced by industries. In the cases where such integration is lacking, there are indications that an increasing gap exists between industry requirements and academic learning. This is because industry requirements expand exponentially [29-33] and deviate from any static curriculum. It would also make academic learning (thus HE) irrelevant when it fails to address such needs. Late adoption decreases the worthiness of graduates in industry. This implies that the HE systems on CS curriculum 
review process should be expedited for the CS offerings to remain up-to-date and maintain relevance. The relevance fades when the gap between industries' advances when the academic syllabus is static. As a result, policymakers can allow CS syllabi to be updated quicker than other academic subjects.

The core CS syllabus of HEI is not reduced when IST is given to students, as it is presented to students in total. The added component is the industry-specific content, which is more in line with the induction training given to new employees. This component is given to augment the theoretical knowledge from the courses given in lectures on the core syllabus. It will, however, include relevant updates from the industry. The IST, therefore, ensures that the core syllabus is relevant in the workplace. Therefore, one of the ways of retaining relevance in CSC is by considering and implementing IST integration into the mainstream university programmes.

\section{Recommendations}

The CSC should be reviewed regularly to keep up with the subject's rapid changes as to maintain its relevance. The university should also introduce electives/open courses focusing on integrating new CS topics.

The idea of having conferences, collaborations and increased networks with industry on vocational training is one way of having ISP in academia. "Reference [1]" points out that these organisations have an important role in workplace awareness. They would enable academia to promote professional practices and increased CS graduate maturity in IT competencies. Organisations would provide mentorship, special presentations to students on the organisation, work related issues, in-house instructional materials, specialised and applied research, and developmental processes in industry.

\section{REFERENCES}

[1] ACM/IEEE. 2017. Information technology curricula 2017. Curriculum guidelines for baccalaureate degree programs in information technology. A report in the computing series. Task group on information technology curricula. Association for Computer Machinery (ACM), Institute of Electrical and Electronics Engineers (IEEE). Online available https://dl.acm.org/citation.cfm?id=3173161>.

[2] Dessinger, T. 2006. The German 'philosophy' of linking academic and work-based learning in higher education: the case of the 'vocational academies', Journal of Vocational Education and Training, 52:4, 605-626, DOI: $10.1080 / 13636820000200134$ Online available from https://www.tandfonline.com/doi/abs/10.1080/1363682000 0200134.
[3] B. Dalgarno, G. Kennedy, G. A. Merritt. Connecting Student Learning at University with Professional Practice Using Rich Media in Practice-Based Curricula. In M. Gosper, D. Ifenthaler (Ed) Curriculum Models for the 21st Century Using Learning Technologies in Higher Education. Springer, London, 2014.

[4] D. Breznitz. (2020). Collaborative Public Space in a National Innovation System: A Case Study of the Israeli Military's Impact on the Software Industry. Online available from https://www.researchgate.net/profile/Dan-B reznitz/publication/227615889_Collaborative_Public_Spac $\mathrm{e}$ in A National Innovation System A Case Study of the_Israeli_Military\%27s_Impact_on_the_Software_Indus try/links/553904e40cf2239 f4e 7b $4 \bar{d}$ 95/Collaborative-Public -Space-in-A-National-Innovation-System-A-Case-Study-of -the-Israeli-Militarys-Impact-on-the-Software-Industry.pdf

[5] H. Izushi, Y. Aoyama, Y. Industry Evolution and Cross-Sectoral Skill Transfers: A Comparative Analysis of the Video Game Industry in Japan, the United States, and the United Kingdom. Environment and Planning A: Economy and Space. 38(10):1843-1861. Doi: 10.1068/a37205, 2006.

[6] S. M. Drake, R. C. Burns, R.C. 2004. Meeting standards through integrated curriculum, Online available from https://2018/Research\%202017/2018/ what $\% 20$ Is\%20Integrated\%20Curriculum_html.

[7] B. Eynon, L. M. Gambino, J. Török, J. 2014. Reflection, integration, and ePortfolio pedagogy, Online available from http://c2l.mcnrc.org/pedagogy/ped-analysis/.

[8] K. Lake. Integrated curriculum. School Improvement Research Series, Office of Educational Research and Improvement, U.S. Department of Education, New York, 1994.

[9] M. Papadakis, M. Kalogiannakis, M. Evaluating a course for teaching introductory programming with Scratch to pre-service kindergarten teachers. International Journal of Technology Enhanced Learning, 11(3), 231-246, 2019.

[10] Department of Higher Education and Training. Higher education qualification framework handbook, Online available from https:/www.che.ac.za/sites/default/files/pu blications/HEQF_Implementation_Handbook.pdf, 2015.

[11] S. Boyd. Integrated curriculum: Definitions, benefits and example, Online available from https://study.com/academy /lesson/integrated-curriculum-definition-benefits-examples .html, 2018.

[12] Hanover Research Council. Best practices in online teaching strategies. Academy Administration Practice, Washington DC, 2009.

[13] B. Alvarez. Flipping the classroom: Homework in class, lessons at home. Education Digest: Essential Readings Condensed for Quick Review, 77 (8): 18-21, 2011.

[14] M. Fullan, S. Striegelbauer. The new meaning of educational change. Cassell, London, 1991.

[15] S. Saedah, C. Wye, C. Futuristic business studies curriculum: A framework, Online available from https://www.researchgate.net/publication/283349073_FUT URISTIC_BUSINESS_STUDIES_CURRICULUM_A_F RAMEWŌRK, 2015. 
[16] J. E. Ormrod. Educational psychology: Developing learners (4th ed.), Merrill Prentice Hall, Upper Saddle River, 2003.

[17] S. Arnold-Garza. The flipped classroom teaching model and its use for information instruction. Communications in Information Literacy, 8 (1): 7-23. 2014.

[18] J. Bergmann, A. Sams. Flip your classroom: reach every student in every class every day, Online available from https://www.iste.org/resources/product?ID=2285, 2012.

[19] B. A. Brown. Understanding the flipped classroom: Types, uses and reactions to a modern and evolving pedagogy, Online available fromhttps://repository.stcloudstate.edu/cg i/viewcontent.cgi?referer=https://www.google.co.za/\&http sredir $=1 \&$ article $=1010 \&$ context=ed_etds, 2016.

[20] M. J. Large, G. Platt, M. Treglia. Inverting the classroom: A gateway to creating an inclusive learning environment. The Journal of Economic Education, 31 (1): 30-43, 2000.

[21] L. Altemueller, C. Lindquist. Flipped classroom instruction for inclusive learning. British Journal of Special Education, 44 (3): 341-358, 2017.

[22] L. Abeysekera, P. Dawsona. Motivation and cognitive load in the flipped classroom: Definition, rationale and a call for research. Higher Education Research \& Development, 34 (1): 1-14, 2015.

[23] N. Yujing. Influence of flipped classroom on learner's empowerment - A study based on English writing courses in China. Journal of Literature, Languages and Linguistics, 12: 1-27, 2015.

[24] T. Hungwe, R. Dagada. Blended learning approach Perceptions in higher education, LAP LAMBERT Academic Publishing, Saarbrucken, 2013.
[25] R. T. Osguthorpe, C. R. Graham. Blended learning environments. Definitions and directions. The Quarterly Review of Distance Education, 4 (3): 227-233, 2003.

[26] H. Singh. Building effective blended learning programs. Educational Technology, 43 (6): 51-54, 2003.

[27] D. R. Garrison, H. Kanuka. Blended learning: Uncovering its transformative potential in higher education. Internet and Higher Education, 7: 95-105, 2004.

[28] A. Burns. Action research: an evolving paradigm?, Online available fromhttps://www.researchgate.net/publication/23 1823715_Action_research_An_evolving_paradigm, 2005.

[29] V. Charchra. Leading into today's ever-changing business environment. Country Manager, India: Harvard Business Publishing, Online available from https://trainingmag.com, 2015.

[30] Deloitte. The digital workplace: Think, share, do transform your employee experience, Online available from https://www2.deloitte.com/content/dam/Deloitte/mx/Docu ments/human-capital/The_digital_workplace.pdf, 2011.

[31] E. Felipe Zecca da Cruz, A. Alvaro. Introduction of entrepreneurship and innovation subjects in a computer science course in Brazil. Proceedings - Frontiers in Education Conference. 1881-1887.10.1109/FIE.2013.6685 $162,2013$.

[32] S. M. Ryan. Capacity expansion with lead times and correlated random demand. Naval Research Logistics, 50(2), 167-183, 2003.

[33] T. N. Srinivasan. Geometric rate of growth of demand. Investments for Capacity Expansion: Size, Location, and Time-Phasing, In A. S. Manne, (ed.), MIT Press, Cambridge, pp. 150-156, 1967. 